NBER WORKING PAPER SERIES

MARKUP BEHAVIOR IN DURABLE AND NONDURABLE MANUFACTURING: A PRODUCTION THEORY APPROACH

Catherine J. Morrison

Working Paper No. 2941

NATIONAL BUREAU OF ECONOMIC RESEARCH

1050 Massachusetts Avenue

Cambridge, MA 02138

Apri1 1989

Research support from the National Science Foundation, Grant \#SES87-08211, is gratefully acknowledged. This paper is part of NBER's research program in Productivity. Any opinions expressed are those of the author not those of the National Bureau of Economic Research. 


\section{MARKUP BEHAVIOR IN DURABLE AND NONDURABLE MANUFACTURING: A PRODUCTION THEORY APPROACH}

\section{ABSTRACT}

In this paper I provide a production theory-based framework for measuring markups of price over marginal cost, and the effects of cost and demand characteristics on these markups. Price to marginal cost ratios are measured for various Canadian manufacturing industries, and the impacts of capacity utilization, scale economies, changing prices of varlable inputs, import competition, unemployment and other cost and demand determinants are evaluated using adjusted markup indexes and elasticities of the markup ratios. The measured price margins are within a reasonable range and tend to be countercyclical. Moreover, these measures suggest that profitability stemming from the potential to increase price over marginal cost appears primarily to arise from cost characteristics determining scale economies. 


\section{The Production Framework and Questions to Consider}

In the past few years researchers dealing with macroeconomic, international trade and industrial organization issues have begun to refocus attention on the importance of market power, and the resulting markups of price over marginal cost. Hall [1988a], for example, based on a model with a macroeconomic perspective, measured markups of price over marginal cost in U.S. manufacturing using a Solow productivity equation approach. He found these markups to be significant and suggested that capacity utilization fluctuations were closely linked to markup levels; labor hoarding and returns to scale did not seem to have an impact on these levels. Schembri [1988] considered the relationship between markup behavior and exchange rate fluctuations in a Canadian export industry, and found evidence that markups cushion the impact of exchange rate variations by allowing firms to absorb short run decreases in prices. Other researchers such as Rotemberg and Saloner [1986], Bils [1985,1987] and Domowitz, Hubbard and Petersen [1987, 1988], using more industrial organization based models, have studied the behavior of the markup over the business cycle. Several of these researchers have found that markups are countercyclical because in booms marginal cost increases more rapidly than price with the expansion of production, while the reverse occurs during downturns.

Domowitz, Hubbard and Peterson [1988] in particular have focused on these patterns of markup behavior. They have estimated markup trends by expanding the Hall [1988a] model to include time varying parameters and intermediate material inputs, using disaggregated data for various manufacturing industries. They conclude that with these adaptations to the 
framework markups appear lower than Hall found, and that when durable and nondurable goods are distinguished ${ }^{1}$ nondurable goods appear to have procyclical markups. In terms of the correlation between capacity utilization and the markup, this has a strong enough impact to cause the overall tendency to be procyclical.

Domowitz et al [1987, 1988] pursued this further and considered the impact on markups of import competition, unemployment, fixed labor (union contracts), industry concentration, and noncapital fixed costs (overhead labor and advertising) and found that these characteristics of the demand and production structure have important effects on the time trends of markups. Among others, Shapiro [1988] has noted ${ }^{2}$ that these results suggest economies of scale and other cost characteristics might affect markups, contrary to the position taken by Hall.

Although these studies have been very important for focusing attention on patterns of markup behavior and their differences across industries, they have not taken advantage of the theoretical basis for the representation of technology - - and thus markup behavior - - provided by duality theory-based production models. Such models are based on cost and demand functions facing a profit-maximizing firm, where the functions characterize the pattern of demand and supply responses of the firm. Since in this framework the cost and

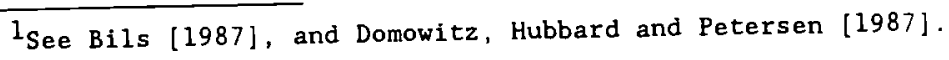

${ }^{2}$ Bils [1987] has incorporated returns to scale and suggested the importance of this characteristic of the production technology. Other researchers such as Romer [1986] have also pointed out its importance in the aggregate.

Shapiro emphasized this more in the context of the current markup model when he outlined the treatment of markup behavior in Appelbaum [1982] and attributed the low and fairly constant level of market power estimated to the restrictions on the cost function in the model. 
demand curves can be measured, the dependence of the firms' optimal markup behavior on these functions and their changes in response to varying economic conditions can be assessed directly. These models allow explicit incorporation of many characteristics of the production structure of firms, like slow adjustment of capital and labor inputs, intermediate input demand and economies of scale. They also allow varying demand conditions across industries to be specified, and the impacts of such factors as import competition and unemployment on demand behavior to be incorporated explicitly. They therefore permit consideration of most markup determinants found to be important by Domowitz et al, and are rich in their potential for interpretation of markup behavior.

More specifically, in a model based on a restricted cost function explicit representation of short and long run marginal and average cost curves is possible. This is important for imputing the patterns of markups since direct measures of the differences between marginal and average costs and their differential responses to exogenous changes are difficult if not impossible to capture in a nonparametric form. ${ }^{3}$ Price determination may be incorporated in this type of theoretical structure by including the firm's output demand function in the optimization model as in Appelbaum [1979, 1982] and Morrison [1982, 1988d]. In this framework the price-setting behavior of

\footnotetext{
${ }^{3}$ See Domowitz, Hubbard and Petersen [1987] for further discussion. If constant returns exist, these measures will coincide. However, evidence from a number of researchers, including Morrison [1988d], Romer [1986], Hall [1988b], Berndt and Khaled [1979] and Shapiro [1988] suggest that this is not the case and that the assumption of constant unit costs in fact causes distortions in markup measures. Domowitz et al also show that even if price cost margins estimated using average costs are procyclical, measures based on marginal costs could be countercyclical depending on the relationship between marginal and average costs during the cycle.
} 
the firm may be modeled from the first order conditions for profit maximization. Since both output price $\left(P_{Y}\right)$ and marginal cost $(M C)$ components of the markup or price ratio $\mathrm{PY}_{\mathrm{Y}} / \mathrm{MC}$ (PRAT) are therefore independently represented, the markup may be calculated directly.

The impact of market fluctuations on the markup measure may also be determined empirically since this ratio, through its dependence on the cost and demand functions, is a function of the supply and demand parameters of the model. By measuring the sensitivity of price and marginal cost to forces affecting output demand or costs in terms of elasticities, this allows consideration of the relative importance of the impact of various exogenous changes that may be thought of as demand or supply "shocks" or cyclical effects. Second order elasticities which indicate the change in the elasticity of demand with changes in cyclical demand side variables may also provide useful information. 4

In subsequent sections the use of a production theory-oriented structural model of firm behavior for assessment and interpretation of markup behavior is evaluated theoretically and empirically. The theoretical structure is based on a generalized Leontief (GL) production technology approach to specification of restricted cost and expenditure functions. This framework permits assessment of the effects of fixed factors such as capital and labor and nonconstant returns to scale. The empirically implementable framework is then applied to measurement of the demand and supply structure for a number of manufacturing industries in Canada from 1960 through 1982.

\footnotetext{
${ }^{4}$ This allows testing of a hypothesis mentioned, for example, by Bils [1985], that the elasticity of demand is procyclical.
} 
The resulting estimated indexes of markup levels, capacity utilization and returns to scale, and elasticities of changes in these indexes in response to fluctuations in exogenous variables, facilitate the interpretation of markup behavior in these industries.

\section{The Model and its Role in Assessing the Issues}

The theoretical model for this study is a dynamic profit-maximizing factor demand model with imperfect competition based on a nonconstant restricted cost function, G. G is assumed to be a function of two variable input prices, $P_{E}$, the price of energy (E) and $P_{M}$, the price of intermediate materials (M), two quasi-fixed inputs with the degree of fixity endogenous to the model, capital ( $K$ with investment $\Delta K$ ) and labor ( $L$ with adjustment in employment $\Delta \mathrm{L})$, output $(Y)$, and the state of technology $(t)$; $G-G\left(P_{E}, P_{M}, K, L, Y, t, \Delta K, \Delta L\right)$. This function is dual to a production function $Y-Y(E, M, K, \Delta K, I, \Delta L, t)$. The firm is also assumed to face a downward sloping demand curve for its output, which is represented by the demand function $Y=D\left(P_{Y}, P_{I M}, r, E X P, P_{C P I}, U N\right)$, where $P_{I M}$ is the price of imports (representing the motivation to consume domestically produced goods), $r$ is the interest rate (affecting the desirability of durable goods), EXP is expenditure, (representing the overall consumption level), PCPI is the cost of living (prices of other products), and UN is the unemployment rate. Thus the specification includes both prices of alternative goods and shift or "state of the world" variables such as unemployment. It can also be represented by the inverse demand function $\mathrm{P}_{\mathrm{Y}}=\mathrm{D}^{-1}\left(\mathrm{Y}, \mathrm{P}_{\mathrm{IM}}, \mathrm{r}, \mathrm{EXP}, \mathrm{P}_{\mathrm{CPI}}, \mathrm{UN}\right)$.

In the short run the stocks of capital and labor, as well as technology and variable input prices are assumed to be given to the firm, although output 
or output price and adjustment of the stocks of capital and labor are endogenous due to the incorporation of the demand equation and internal adjustment costs. Adjustment costs are built into the cost function through incorporation of $\Delta \mathrm{K}$ and $\Delta \mathrm{L}$ as arguments of the function, and are interpreted as representing the reduced potential for output production with the existing variable inputs when changes in these stocks occur.

This specification accommodates numerous characteristics which have been postulated to be important in the literature. For example, it allows for labor fixity, which may arise from labor hoarding, unionization or overhead labor, and for its adjustment to be endogenous. It also includes fixity of capital, which, with labor fixity, determines the amount of available capacity. The potential for excess capacity due to slow adjustment of inputs can therefore be directly analyzed. The importance of both energy and nonenergy intermediate materials is also recognized in this specification. A sloped marginal cost function is not ruled out, which may be particularly important for modeling nonconstant markups. Also, since these marginal costs can directly be measured as the derivative $\partial G / \partial Y$, the difference between marginal and average costs can explicitly be determined, which is a great advantage over traditional methods outlined by Domowitz et al which approximate marginal cost by average variable cost. Finally, the specification of the demand function explicitly recognizes the importance of import competition and unemployment on demand for manufactured products.

Given these functions and relationships, the firm's intertemporal profit maximization problem is 
1) $\operatorname{Max}_{Y, \Delta K, \Delta L} R(0)=\int_{0}^{\infty} e^{-r t} P_{Y t}\left(Y_{t}\right) Y_{t}-G\left(P_{E t}, P_{M t}, Y_{t}, K_{t}, \Delta K_{t}, L, \Delta L\right)$

$$
\begin{aligned}
& -a_{K t} z_{K} \cdot a_{L t} z_{L t} d t \\
& -\int_{0}^{\infty} e^{-r t}\left(P_{Y_{t}}\left(Y_{t}\right) Y_{t}-G\left(P_{E t}, P_{M t}, Y_{t}, K_{t}, \Delta K_{t}, L, \Delta L\right)-a_{K t} \delta K_{t}\right) d t \\
& -\int_{0}^{\infty} e^{-r t} a_{K t} \Delta K_{t} d t-\int_{0}^{\infty} e^{-r t} a_{L t} \Delta L t d t
\end{aligned}
$$

where $\delta_{K}$ is the depreciation rate for capital, $a_{K}$ is the initial purchase or asset price of capital, and $z_{K}=\Delta K+\delta K$ is gross investment in capital; treatment of labor is symmetric except that $\delta_{L}$ is assumed to be zero.

Optimization over the variable inputs is reflected in the normalized restricted variable cost function $G ;^{5}$ by definition this function captures minimum variable costs conditional on $\mathrm{K}, \Delta \mathrm{K}, \mathrm{L}, \Delta \mathrm{L}$ and $\mathrm{Y}$. $\mathrm{G}$ is assumed to be approximated by a nonconstant returns to scale (NCRTS) generalized Leontief (GL) restricted cost function developed by Morrison [1988b].6

\footnotetext{
5 The process of constructing this dual cost function is outlined in Berndt, Fuss and Waverman [1980] and Morrison and Berndt [1981].

${ }^{6}$ The properties of this function are outlined in greater detail in Morrison [1988b]. Note that specifying nonconstant returns for a function that will be estimated in the aggregate is ambiguous. In particular, unless there are proportional movements in relative sectoral growth, the computation of a level of returns to scale for an entire industry using this function does not reflect a level of returns for any particular firm. Although constant returns is often assumed to circumvent this problem (if all firms are subject to constant returns it may be assumed that a constant returns function reasonably characterizes the industry), this seems too limiting. Preliminary empirical investigation of the data, as well as previous studies such as Berndt and Khaled [1979], suggest that the assumption of nonconstant returns to scale is important for generating reasonable estimates. Berndt and Khaled, in fact, find returns to scale for the U.S. similar to those found in this study for Canada. In addition, studies of markups such as Hall [1988a] imply that returns to scale may be important for correctly considering the markup. Therefore, the nonconstant returns to scale function will be utilized even though aggregation difficulties imply that interpretation of the resulting returns to scale estimates is unclear.
} 
2) $G=Y\left[\sum_{i} \sum_{j} \alpha_{i j} p_{i}^{.5} p_{j}^{.5}+\sum_{i} \sum_{m} \delta_{i m} p_{i} s_{m}^{.5}+\sum_{i} p_{i} \sum_{m} \sum_{n} \gamma_{m n} s_{m}^{.5} s_{n}^{.5}\right]$

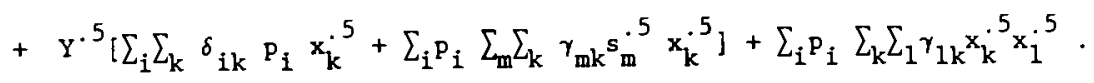

where $P_{i}$ and $P_{j}$ index the prices of variable inputs $E$ and $M, s_{m}, s_{n}$ denote $Y$, $t, \Delta K$ and $\Delta L$, and $x_{k}, x_{1}$ represent $K$ and $L$.

Given this function, optimal short run input demand levels can be specified as $\partial G / \partial \mathrm{P}_{E}=\mathrm{E}=\mathrm{v}_{\mathrm{E}}$ and $\partial G / \partial \mathrm{P}_{M}=\mathrm{M}=\mathrm{v}_{\mathrm{M}}$ by Hotelling's lemma:

$$
\text { 3) } \begin{aligned}
v_{i}= & \frac{\partial G}{\partial p_{i}}=Y\left[\sum_{j} \alpha_{i j}\left(p_{j} / p_{i}\right)^{.5}+\sum_{m} \delta_{i m} s_{m}^{.5}+\sum_{m} \sum_{n} \gamma_{m n} s_{m}^{.5} s_{n}^{.5}\right] \\
& +Y^{5}\left[\sum_{k} \delta_{i k} x_{k}^{.5}+\sum_{m} \sum_{k} \gamma_{m k} s_{m}^{.5} x_{k}^{.5}\right]+\sum_{k} \sum_{1} \gamma_{1 k} x_{k}^{.5} x_{i}^{5}
\end{aligned}
$$

The next step of the optimization process is to choose the profit maximizing output conditional on the levels of $K, \Delta K, L$, and $\Delta L$. This requires maximizing $D^{-1}(\bullet) Y-G(\bullet)$ with respect to $Y$, similarly to Appelbaum [1979]. The solution to this problem can be characterized by the standard equality of marginal revenue (MR) and $M C$

4) $M R=D^{-1}\left(Y, P_{I M}, r, E X P, P_{C P I}, U N\right)+Y \bullet \partial D^{-1}\left(Y, P_{I M}, r, E X P, P_{C P I}, U N\right) / \partial Y$

$$
\begin{aligned}
& =\partial G\left(P_{E}, P_{M}, K, \Delta K, L, \Delta L, t, Y\right) / \partial Y=M C, \text { or } \\
P_{Y} & =-Y \bullet \partial D^{-1} / \partial Y+\partial G / \partial Y .
\end{aligned}
$$

Constructing this expression requires an additional functional form assumption for the inverse demand equation $D^{-1}\left(Y, P_{I M}, r, E X P, P_{C P I}, U N\right)$. This equation is based on the demand function ${ }^{7}$

${ }^{7}$ See Morrison [1988d] for further discussion. 
5) $D\left(\rho, \mathrm{P}_{\mathrm{Y}}\right)=\mathrm{D}\left(\mathrm{EXP}_{,} \mathrm{P}_{\mathrm{IM}}, \mathrm{r}, \mathrm{P}_{\mathrm{CPI}}, \mathrm{UN}, \mathrm{P}_{\mathrm{Y}}\right)-D\left(\rho, \mathrm{P}_{\mathrm{Y}}\right)=\mathrm{Y}-\sum_{\mathrm{h}}{ }_{\mathrm{Yh}} \rho_{\mathrm{h}}^{.5} \mathrm{P}_{\mathrm{Y}}^{-.5}+\beta_{\mathrm{YU}} \mathrm{UN}^{.5}$.

where $h$ indexes the variables contained in the vector of shift parameters $p$ except UN which is not normalized in the demand function. This functional form has the desirable property that it guarantees homogeneity of degree zero in prices and expenditure, which is required for consistency with a utility maximization problem; it is structurally similar to the factor demand equations used as a basis for analysis.

Solving for $\mathrm{P}_{\mathrm{Y}}$ in terms of $\mathrm{Y}$ generates the inverse demand function, taking the derivative of this with respect to $\mathrm{Y}$ yields $\partial D^{-1} / \partial \mathrm{Y}$, and computation of $\partial G / \partial Y$ can be accomplished using (2). These expressions can then be substituted into (4) to generate the optimal output price equation

6) $\mathrm{P}_{\mathrm{Y}}=-\mathrm{Y}\left\{-2\left[\frac{\left(\sum_{\mathrm{h}} \beta_{\mathrm{Yh}}{ }^{\rho_{\mathrm{h}}^{5}}\right)^{3}}{\left(\mathrm{Y}-\beta_{\mathrm{YU}} \mathrm{UN}^{3}\right.}\right\}^{2}\right.$

$$
\begin{aligned}
& +\sum_{i} \sum_{j} \alpha_{i j} p_{i}^{.5} p_{j}^{.5}+\sum_{i} \sum_{m} \delta_{i m} p_{i} s_{m}^{.5}+\sum_{i} p_{i} \sum_{m} \sum_{n} \gamma_{m n} s_{m}^{.5} s_{n}^{.5} \\
& +.5 Y^{-.5}\left[\sum_{i} \sum_{k} \delta_{i k} p_{i} x_{k}^{.5}+\sum_{i} p_{i} \sum_{m} \sum_{k} \gamma_{m} s_{m}^{.5} x_{k} \cdot 5\right. \\
& +.5 Y^{.5}\left[\sum_{i} \delta_{i Y} p_{i}+\sum_{i} p_{i} \sum_{m} \gamma_{m Y} s_{m}^{.5}\right]+.5 \sum_{i} p_{i} \sum_{k} \gamma_{Y k} x_{k} .
\end{aligned}
$$

Note that since $\partial G / \partial Y$ is a function of all arguments of $G$, any supply or cost shock captured by the cost function will have an explicit impact on MC and therefore on the markup. In addition, since $\mathrm{Y}\left(\mathrm{PY}_{\mathrm{Y}}\right)$ is nonlinear in $\mathrm{PY}_{\mathrm{Y}}$, all 
shift parameters representing demand shocks affect the elasticity of demand for produced output and therefore the markup.

The final step in the maximization process involves choosing the paths of the fixed inputs to optimize the present value of total net receipts. This requires solving ( 1 ) with the optimized values for output price and variable input quantities substituted and expressing the solution to this problem in terms of the Euler necessary conditions (in continuous time):

7) $-G_{k}-r G_{k}-P_{k}+G_{k k} \dot{x}_{k}+G_{k k} \dot{x}_{k}=0$,

where $\mathrm{x}_{\mathrm{k}}$ is $\mathrm{dx}_{\mathrm{k}} / \mathrm{dt}$, reflecting $\Delta \mathrm{K}$ or $\Delta \mathrm{L}$ in a continuous time framework, $\mathrm{x}_{\mathrm{k}} \cdot$ denotes the second derivative of capital or labor with respect to time, and $\mathrm{P}_{\mathrm{K}}=\mathrm{a}_{\mathrm{K}}\left(\mathrm{r}+\delta_{\mathrm{K}}\right)$ and $\mathrm{P}_{\mathrm{L}}=\mathrm{a}_{\mathrm{L}}$ represent the vectors of ex-ante costs of capital and labor. Substituting for $G_{k}$ and $G_{\Delta k}$ results in

$$
\begin{aligned}
& \mathrm{p}_{\mathrm{k}}=-.5\left[\sum_{\mathrm{i}} \mathrm{p}_{\mathrm{i}} \sum_{1} \gamma_{\mathrm{k}]_{\mathrm{k}}} \mathrm{x}_{\mathrm{k}}^{-.5} \mathrm{x}_{\mathrm{l}}^{.5}+\mathrm{y}^{.5} \mathrm{x}_{\mathrm{k}}^{-.5}\left(\sum_{\mathrm{i}} \delta_{\mathrm{ik}} \mathrm{p}_{\mathrm{i}}+\sum_{\mathrm{i}} \mathrm{p}_{\mathrm{i}} \sum_{\mathrm{m}} \gamma_{\mathrm{mk}} \mathrm{s}_{\mathrm{m}}^{.5}\right)\right], \\
& -.5 r \Delta x_{k}^{-.5}\left[Y\left(\sum_{i} \delta_{i k} p_{i}+\sum_{i} p_{i} \sum_{m} \gamma_{m k} s_{m}^{.5}\right)+Y^{.5} \sum_{i} p_{i} \sum_{k} \gamma_{k k} x_{k}^{.5}\right] \\
& -\Delta^{2} \mathrm{x} \cdot 25 \Delta \mathrm{x}_{\mathrm{k}}^{-1.5}\left[\mathrm{Y}\left(\sum_{\mathrm{i}} \delta_{\mathrm{ik}} \mathrm{P}_{\mathrm{i}}+\sum_{\mathrm{i}} \mathrm{p}_{\mathrm{i}} \sum_{\mathrm{m}} \gamma_{\mathrm{mk}} \mathrm{s}_{\mathrm{m}}^{.5}\right)+\mathrm{Y} \cdot{ }^{5} \sum_{\mathrm{i}} \mathrm{p}_{\mathrm{i}} \sum_{\mathrm{k}} \gamma_{k \mathrm{k}} \mathrm{x}_{\mathrm{k}}^{.5}\right] \\
& +.5 Y^{.5} x_{k}^{-.5} x_{k}^{.5} \sum_{i} p_{i} \gamma_{k k}
\end{aligned}
$$

for each quasi-fixed input.

The system of equations (3), (5), (6), and (8) represents optimal variable input demands, the demand function for output, the profit maximizing price level and the optimal paths of the fixed inputs. This summarizes the solution to the overall profit maximization problem. Estimation of this 
system generates parameter estimates that represent all input and output decisions of the firm, and therefore also reflects markup behavior, capacity utilization (CU) and economies of scale or returns to scale (RTS).

In particular, measuring the markup simply requires computing the price determination equation (6) and dividing it by the implied expression for $\partial G / \partial Y-M C$ to obtain PRAT $\mathrm{PY}_{\mathrm{M}}$ MC. ${ }^{8}$ This measure depends on the inverse demand elasticity, since $\mathrm{PY}_{\mathrm{Y}} / \mathrm{MC}=\mathrm{P}_{\mathrm{Y}} /\left(\mathrm{Y} \partial \mathrm{p}_{\mathrm{Y}} / \partial \mathrm{Y}+\mathrm{P}_{\mathrm{Y}}\right)=1 /(1+\epsilon \mathrm{PY})$ with profit maximization, where $\epsilon_{\mathrm{PY}}$ represents the inverse demand elasticity with respect to output.

The size and significance of this elasticity is therefore important for consideration of markups. The size can easily be determined by computing the elasticity directly from the inverse demand function as $\epsilon_{\mathrm{PY}}=\partial \ln \mathrm{D}^{-1} / \partial \mathrm{ln} \mathrm{Y}$, and its statistical significance can be tested by constructing a standard error for the measure. ${ }^{9}$ Using these values the null hypothesis of no markup behavior can be tested by determining if the inverse demand elasticity is zero. In addition, these relationships imply that the standard demand elasticity $\partial \ln \mathrm{Y} / \partial \ln \mathrm{PY}_{\mathrm{Y}}=\epsilon_{\mathrm{YP}}-1 / \epsilon_{\mathrm{PY}}$ can be computed as $\epsilon_{\mathrm{YP}}=-\mathrm{PRAT} /(1-\mathrm{PRAT})$. The impact on the markup level of technological characteristics and other exogenous economic factors can be computed in various ways. The implied

\footnotetext{
${ }^{8}$ Note that markups may also be expressed in alternative ways which generally contain the same information. For example, common measures of market power

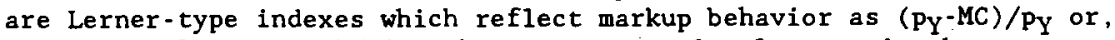
alternatively, $\left(P_{Y}-M C\right) / M C$. These measures clearly contain the same information as PRAT because they can be written as 1-(1/PRAT) and PRAT-1, respectively.

${ }^{9}$ Since this elasticity represents the demand function, its elasticities with respect to arguments of the demand function can in turn be computed to show how the function will change with demand shocks. These second-order elasticities are analogous to those discussed as biases in Morrison [1988c] and show how the demand elasticity changes as shifts in the demand function occur over the cycle. Although they provide useful information, they will not be discussed here due to space constraints.
} 
markup level if constant returns to scale or instantaneous adjustment existed, for example, can be inferred simply by multiplying the markup measure by $1 /$ RTS and $\mathrm{CU}$ indexes. The effect of exogenous changes, such as input price or technical change variations (supply shocks) or unemployment or import price fluctuations (demand shocks) can be measured using elasticities of the markup measure with respect to these arguments of the function. I will now outline these computations in turn.

First, note that RTS and CU are both reflected in the cost elasticity with respect to output, $\epsilon_{\mathrm{CY}}=\partial \operatorname{lnC} / \partial \ln \mathrm{Y}-\mathrm{MC} \bullet \mathrm{Y} / \mathrm{C}$, where $\mathrm{C}$ is total costs, $G+p_{K} K+p_{L} L$. In the special case of constant returns to scale and no fixity of inputs this measure will be equal to one. Otherwise its value will be a multiplicative combination of indexes representing these two characteristics of the technology. Specifically, Morrison [1986, 1988a,d,e] has shown that ${ }^{\epsilon} \mathrm{CY}=\epsilon \mathrm{CY}{ }^{\mathrm{L}} \mathrm{CU} \mathrm{C}_{\mathrm{C}}$, where $\epsilon_{\mathrm{CY}}{ }^{\mathrm{L}}$ represents the long run cost elasticity with respect to output 10 (the inverse of long run returns to scale), $\mathrm{CU}_{c}$ is the cost-side CU measure $C * / C$, and $C *$ is shadow costs, $G+\sum_{k} Z_{k} x_{k}$. Note that when fixity is not an issue, so $\mathrm{Z}_{\mathrm{k}}=\mathrm{P}_{\mathrm{k}}, \epsilon_{\mathrm{CY}}=\epsilon_{\mathrm{CYL}}=1 / \mathrm{RTS}$ only represents returns to scale, and when constant returns exist so $\epsilon_{\mathrm{CY}}{ }^{\mathrm{L}}=1, \epsilon_{\mathrm{CY}}-\mathrm{CU}_{\mathrm{c}}$ captures only the fixity of inputs.

Using these measures to determine the impact on markups of the corresponding characteristics of the technology is somewhat more complex to motivate and interpret. It is useful to envisage the profitability of the firm from the deviation of $P_{Y}$ from average cost $(A C)^{11}$ as being composed of

\footnotetext{
${ }^{10}$ See Morrison [1988a] for further development of this measure and discussion of more complex nonhomotheticity results.

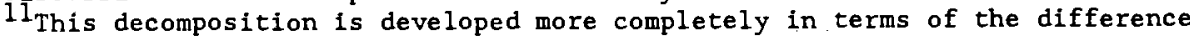
between revenues $\left(\mathrm{P}_{Y} \mathrm{Y}\right.$ ) and total costs (C) in Morrison [1988e].
} 
three parts: (i) the difference between $C * / Y$ and $C / Y-A C$, reflecting subequilibrium; (ii) the difference between $A C$ and $M C$, arising from the existence of scale economies; and (iii) the difference between $p_{Y}$ and MC due to market power. 12 This is equivalent to the decomposition of the deviation between revenues ( $\mathrm{PY}_{Y} \mathrm{Y}$ ) and costs (C) In Morrison [1988e] as $\mathrm{p}_{\mathrm{Y}} \mathrm{Y}-\mathrm{C}\left[\mathrm{CU}_{\mathrm{c}}{ }^{\epsilon} \mathrm{CY}{ }^{\mathrm{L}}\left(\mathrm{P}_{\mathrm{Y}} / \mathrm{MC}\right)\right]-\epsilon^{\epsilon} \mathrm{CY} C\left(1 /(1+\epsilon \mathrm{PY})\right.$, or $\mathrm{p}_{\mathrm{Y}} / \mathrm{MC}-\mathrm{p}_{\mathrm{Y}} \mathrm{Y} / \epsilon_{\mathrm{C}} \mathrm{CY}$. Therefore to obtain a measure of true profitability without the impacts of subequilibrium and returns to scale, $\mathrm{PY}_{\mathrm{Y}} / \mathrm{AC}$, the $\mathrm{PY} / \mathrm{MC}$ measure must be multiplied by $\epsilon_{\mathrm{CY}}$; to identify the independent contributions of scale economies and fixity this multiplication can be carried out by only one of the two components of ${ }^{c} \mathrm{CY}$, either $\mathrm{CU}_{\mathrm{c}}$ or ${ }^{\epsilon} \mathrm{CY}^{\mathrm{L}}$.

This development can be reinterpreted in terms of the cyclical behavior of the markup. The adjustment for the impact on the markup of ${ }^{\epsilon} \mathrm{CY} \neq 1$ is equivalent to considering both whether CU fluctuations and RTS determine markup behavior, and whether procyclicality exists.

More specifically, Hall [1988a, 1988b] suggested that excess capacity utilization and returns to scale (captured in $\epsilon_{\mathrm{CY}}$ ) will counteract profitability from market power (picked up in $E_{P Y}$ ) so profits would approximate zero even with markups; $\left(\mathrm{PY}_{\mathrm{Y}} / \mathrm{MC}\right) \epsilon_{\mathrm{CY}}-\left(1 /\left(1+\epsilon_{\mathrm{PY}}\right)\right) \epsilon_{\mathrm{CY}}{ }^{-1}$. This is equivalent to carrying out the adjustment suggested above and determining whether real profitability from market power is attenuated by excess capacity

\footnotetext{
12 This distinction can be made more concrete by drawing a diagram of the firm's output choice and dividing the vertical distance between $P_{Y}$ and $M C$ into the distance between the long and short run MC curves (i), the distance between the long run $M C$ curve and the long run $A C$ curve (ii), and the difference between the long run $A C$ curve and the demand curve (iii), where the last measure is the true measure of "profitability" arising only from market structure.
} 
or potential economies of scale. Although such an argument is specified in terms of levels, it also suggests in terms of trends that if an exogenous shock causes markups to increase, it should also cause additional excess capacity or returns to scale. Markups and the (individual or combined) CU and ${ }^{\epsilon} \mathrm{CY}{ }^{\mathrm{L}}$ measures must in this scenario, therefore, move in opposite directions.

This can be linked to cyclical behavior by reference to the the test for cyclical markup behavior in Domowitz et al; they assess cyclicality by comparing markups with $\mathrm{CU}$ indicators. Their argument for procyclicality rests primarily on evidence that capacity utilization (perhaps adjusted for concentration ratios) and markups tend to go in the same direction, except in durable goods industries. The capacity utilization measures they use for comparison are standard published measures rather than economic theoretic measures. Since the Domowitz et al interpretation of the relationship between $\mathrm{PY}_{\mathrm{Y}} / \mathrm{MC}$ and $\mathrm{CU}_{\mathrm{C}}$ is the reverse of that for $\mathrm{Hall}$, and both depend on the relative impacts of capacity utilization and scale economies on the markup, these issues can be considered in the same framework.

Elasticities of the markup indexes with respect to exogenous variables provide additional information about the determinants of markups and their trends. The impact of a change in the price of energy, for example, can be shown to affect the marginal cost curve and therefore the output level chosen, and, finally, PRAT. This mechanism is reflected in the expression for PRAT in (6). The dependence of the price ratio elasticity on both price and marginal cost can be stated using the definition PY/MC-PRAT as:

9) $\frac{\mathrm{d} \ln \text { PRAT }}{\mathrm{d} \ln \rho}=\frac{\rho}{\mathrm{P}_{\mathrm{Y}}}\left[\frac{\partial \mathrm{D}^{-1}}{\partial \rho}-\frac{\partial \mathrm{D}^{-1}}{\partial \mathrm{Y}} \frac{\partial \phi / \partial \rho}{\partial \phi / \partial \mathrm{Y}}\right]+\frac{\rho}{\mathrm{MC}}\left[\frac{\partial \mathrm{MC}}{\partial \mathrm{Y}} \frac{\partial \phi / \partial \rho}{\partial \phi / \partial \mathrm{Y}}\right]$, 
for an elasticity with respect to a demand shock, where $0=\phi(Y, \rho, \gamma)$ is the implicit function for the solved value of $Y$ from (4). 13 This solved value is necessary to incorporate in this elasticity because the simultaneous determination of both price and output must be taken into account to allow for adjustment of output along the supply or demand curve in response to demand or supply shocks.

These elasticities provide important information about the responsiveness of the firm. For example, the hypothesis by some researchers that costs dominate price fixing behavior ${ }^{14}$ may be assessed by determining if elasticities with respect to cost variables are larger than those for demand variables.

In addition, these measures provide information about elasticities of the output demand elasticity $\epsilon_{Y P}$ with respect to demand shocks. For example, it can be shown from the relationship PRAT- $1 /\left(1+\epsilon_{\mathrm{PY}}\right)$ and the definition $\epsilon_{\mathrm{PY}}-1 / \epsilon_{\mathrm{YP}}$ that if $\partial \ln \mathrm{PRAT} / \partial \ln \rho=\alpha,-\partial \ln \epsilon_{\mathrm{PY}} / \partial \ln \rho-\alpha\left[\left(1 / \epsilon_{\mathrm{PY}}\right)+1\right]-$ $\alpha[(\operatorname{PRAT} /(1-\mathrm{PRAT}))+1]=\partial 1 \mathrm{n} \epsilon_{\mathrm{YP}} / \partial \mathrm{ln} \rho$. These estimates could yield important information if, as has been asserted by Rotemberg and Saloner [1986], for example, the cyclical path of markups is driven by an increased elasticity of demand when demand is strong, indicating a more competitive structure.

Perhaps even more importantly, the responsiveness of the cost elasticity ${ }^{\epsilon} \mathrm{CY}$ and 1 ts components $\epsilon_{\mathrm{CY}}{ }^{\mathrm{L}}$ and $\mathrm{CU}_{\mathrm{c}}$ can be computed. These measures provide

${ }^{13}$ For more discussion of these rather complex elasticities, see Morrison [1988d].

14 Among others, this has been suggested by Rotemberg and Summers [1987]. 
information about whether exogenous shocks have a direct or inverse impact on the markup level and $\epsilon_{\mathrm{CY}}$. This allows additional interpretation about cyclical interrelationships among the PRAT, $\mathrm{CU}_{c}$ and $\epsilon_{\mathrm{CY}}{ }^{\mathrm{L}}$ measures. For example, since the impact of demand or supply shocks on PRAT, $\mathrm{CU}_{\mathrm{c}}$ and $\epsilon_{\mathrm{CY}}{ }^{\mathrm{L}}$ may be explicitly modeled, the relative impact of energy price changes or technological developments on these measures and therefore their effect on profitability, may be considered.

\section{Empirical Implications of the Model.}

For estimation, data for various durable and nondurable manufacturing industries in Canada were generously provided by G.C. Watkins of DataMetrics in Calgary, Alberta. These data were used to estimate factor demand, price setting and investment behavior using equations (3), (5), (6) and ( 8 ). The industries considered are Total Manufacturing (MAN), Food and Beverages (FO0), Textiles (TEX), Paper and Allied Products (PAP), Chemicals and Chemical Products (CHM), Iron and Steel (IS), Transportation Equipment (TRQ), and Non Metal Mineral Products (NMP). FOO, TEX, PAP and CHM were combined using Divisia index procedures to generate data for aggregate nondurable manufacturing, and the remaining sectors similarly were combined for durable manufacturing. The industries were estimated separately so a common production function was not imposed on the data. The Euler equation itself, rather than the analytical solution to the condition, was used for estimation, which was carried out by iterative three stage least squares using lagged values of the arguments as instruments, as suggested by Pindyck and Rotemberg [1983]. In this sense, therefore, the model allows for rational expectations. 
Although this data is more disaggregated than that for many studies, the interpretation of the resulting markup, demand elasticity and scale economy measures should be attempted with caution. These measures do not reflect individual demand and cost curves for firms within the industries, but important implications can be obtained from their deviation from competitive and constant returns to scale values. Clearly even more information can be gained by applying these methods to more disaggregated data.

The price ratio (PRAT) estimates PY/MC for each industry, representing the markup, are presented in Table 1 . Note that the indexes tend to increase over time, as has been found by Morrison [1988d] for the U.S. and Japan and by Schembri [1988] for U.S. exported and Canadian domestic goods. In addition to the secular trend, cyclical fluctuations exist; from a first glance the Indexes appear procyclical, with declines in the post-1973 and 1979-80 periods and increases in the 1960s. The varlous industries, however, have experfenced somewhat different markup patterns. Although sectoral detalled analysis is beyond the scope of this paper, it is useful briefly to consider the comparative information generated by these indexes.

The total manufacturing industry markups are in the 78 to $28 \mathrm{z}$ range, very similar to those found for U.S. manufacturing in Morrison [1988d]. They are largest in 1977, although 1973 is also quite high. The 23 markups found in 1973 drop to 18 in 1974, they catch up again by 1977 and drop in $1979-81$. A partial recovery appears to commence in 1982, although the markup only reaches its 1969 value. Similar patterns are found for the textiles industry (with an $8 \%$ to $25 \%$ range), and the iron and steel industry (11-22\%). Although analogous overall trends also appear in the chemicals industry, the markup is 
larger and fluctuates more in the post-1969 years, reaching 628 and 548 in 1973 and 1978. It is worth noting that these numbers suggest fairly elastic demand; ${ }^{15}$ the implied demand elasticities are approximately -11 (for a 108 markup, or PRAT $=1.1$ ) to -5 (for a 258 markup), reaching as low as -2.75 for the chemical industry.

Markups for the food industry tend to be larger and do not increase as much proportionately. They stay fairly constant (16-218) to 1967, jump slightly to 258 in 1968 , stay large through 1973, then drop back to their 1960 level. PRAT increases again in 1976 to 1.23 (a 238 markup) and stays around this level until 1981-82 when the markup reaches 38\%. These values could possibly reflect supply problems for the struggling agricultural sector during the 1980's. These larger markups imply more inelastic demand than for total manufacturing; the demand elasticity is -6 for a 208 markup and -3.5 for a 408 markup.

The paper industry experienced larger levels and fluctuations in its markups for certain years than any of these industries. The markups in this industry range from 108 to 858 , with 858 corresponding to a demand elasticity of -2.2 . This suggests quite inelastic demand facing paper firms in $1971-73$ when the 858 level was reached. In 1974 markups drop to 378 , recover to 778 in 1978, decline to approximately 508 in 1980-81 and finally jump back to 768 in 1982. These large fluctuations may suggest that international competitiveness, which could have smoothed these cycles, was not significant. By contrast the existence of international competition could be partially responsible for the pattern of markups found in the transportation industry,

${ }^{15}$ The corresponding inverse demand elasticities of .09 to .2 are significantly different from zero throughout for these industries. 
which experienced the smallest markups, implying the least market power. Markups increased from 2 to 108 by 1965, reached their largest value (198) in 1970, and then stayed fairly large until 1975 when a decline set in, which caused a drop to 128 in 1977 . Although cycles do exist, there is little evidence of an increase over time after the late 1960s. The competitiveness implied by this is reflected in the implied elasticity of demand of up to -50 (28 markup), and approximately -10 (PRAT-1.11) on average.

Finally, the mineral products industry had large markups over this time period but less time trend than most, starting at 198 , reaching 378 , and then declining to 248 at the end of the sample. Like the food industry, the markups are fairly constant at first, increasing in 1968-70 to about 238 and again more dramatically in 1971-73 to their highest levels, with lower levels from that point except for a temporary "snap-back" in 1978. The typical markup of about 20-258 implies a demand elasticity of -6 to -5 .

Overall, these measures are lower than those estimated by Hall [1988a], although this would be expected since they are based on gross output rather than value added. The values are, however, reasonably consistent with the U.S. measures found by Domowitz, Hubbard and Peterson [1987, 1988]. With the more fully structured model of this paper, however, it is possible to undertake a more complete assessment of the impacts of different technical and market characteristics on the markup level and its cyclicality.

The influence on these markups of fixity of capital and labor inputs and returns to scale can be ascertained from the adjusted measures presented in Tables 2 and 3 . The adjustments for fixity of factors, reflected in the capacity utilization measure $\mathrm{CU}_{c}$, is captured in the measures in Table 2. 
These measures are quite similar to the unadjusted markup measures in Table 1 , and, in fact, often are further from one rather than closer. This arises because the capacity utilization measures tend to exceed rather than fall short of one. In most industries the only years for which $\mathrm{CU}_{\mathrm{c}}$ is less than one are the poor performance years such as post-1973 and 1980-82 and often the first few years of the sample. This augments the cycles found in the markup ratios, which already were lower for these years, since the adjustment simply take the multiplicative form $\left(\mathrm{PY}_{\mathrm{Y}} / \mathrm{MC}\right) \mathrm{CU}_{\mathrm{C}}$. This suggests that if there were instantaneous instead of slow adjustment, markups would tend to be larger and have a stronger cyclical component.

The impact of returns to scale, reflected in the measures in Table 3 , is very different. These measures are consistent with the suggestion in Hall [1988b] that the profitability implied by markups arises from potential returns to scale. When the adjustment for scale is made, the adapted markup measures are much closer to one. If constant returns to scale existed, therefore, the measured markup would appear much closer to one, and sometimes, especially in the textile and paper industries, profitability might be so low as to be negative for some years. Since large markups appeared in the paper industry initially, this suggests substantial returns to scale in this industry, which is intuitively reasonably. For the auto industry virtually all observed profits arise from returns to scale; the adjusted measures approximate one to two digits. ${ }^{16}$ For most industries and years the approximation is correct to one digit.

\footnotetext{
${ }^{16}$ Fuss and Waverman [1986] also found scale economies to be important in the
} U.S. and Japanese automobile industries. 
If the measure of profitability were to be decomposed, therefore, the cost components reflected in $\epsilon_{\mathrm{CY}}$ would tend to compensate for measured profit margins. The most important component of the measure causing this result would, however, be scale economies. Scale economies thus appear to be a good "explanation" of the existence of profit margins when profits appear close to normal - much better than fixity, or, equivalently, capacity utilization.

These results have important implications for interpreting the work by Hall and DHP. In particular, Hall's [1988b] hypothesis about scale economies attenuating profitability is consistent with these results, but his hypothesis in Hall [1988a] about capacity utilization accomplishing this is not supported. This conclusion suggests that the DHP conjecture that capacity utilization and price margins might be positively correlated, so markups are procyclical, might instead be suggested by the data. However, that turns out not to be the case. In fact, if procyclicality arises in these industries, it appears to occur for the durable rather than nondurable industries, reversing the tendency found by DHP. This can be shown be computing the correlations between the price ratio and these components of $\epsilon_{C Y}$, as presented in Table 4. 
Table 4

Correlations between PRAT and $\mathrm{CU}, \epsilon_{\mathrm{CY}}$ and $\epsilon_{\mathrm{CY}}{ }^{\mathrm{L}}$

MAN FOO IEX PAP CHM IS $\underline{\text { TRO NMP }}$ NDUR DUR

$\begin{array}{lllllllllllllll}\mathrm{CU}_{\mathrm{c}} & -. .315 & .344 & -.287 & -.659 & -.471 & .472 & .013 & -.070 & -.006 & -.660\end{array}$

$\begin{array}{lllllllllllllll}\epsilon_{\mathrm{CY}} & -.912 & -.636 & -.970 & -.830 & -.938 & -.637 & -.606 & -.787 & -.987 & -.954\end{array}$

${ }^{\epsilon} \mathrm{CY}^{\mathrm{L}} \quad \begin{array}{llllllllllll} & -.972 & -.907 & -.995 & -.950 & -.986 & -.971 & -.991 & -.979 & -.967 & -.981\end{array}$

These values highlight the important inverse relationship between $\epsilon_{\mathrm{CY}}{ }^{\mathrm{L}}$ (representing scale economies) and PRAT suggested by the adjustments in Table 3. They also show that a similar relationship holds between the overall cost elasticity, $\epsilon_{\mathrm{CY}}$, and PRAT, although it is not as strong. The somewhat surprising implication from these numbers, however, is the countercyclical nature of the price margin (as defined by DHP) from the negative correlation between PRAT and $\mathrm{CU}_{c}$. The industries for which this does not hold are food, iron and steel, and transportation equipment, suggesting that it is more likely for durable than nondurable industries to experience procyclical markups. Aggregation may mask this tendency, however, as seen by the NDUR and DUR columns, where divisia indexes of the individual industries were used for estimation; less countercyclicality appears in the nondurable manufacturing industries according to this measure. 
The elasticities of the markup PRAT and cost elasticity components $\epsilon_{\mathrm{CY}}{ }^{\mathrm{L}}$ and $\mathrm{CU}_{\mathrm{c}}$ provide additional information to facilitate assessment of the determinants of the markup level and cycles. These elasticities tend to be quite robust over time in terms of sign and usually size. This is especially true for total manufacturing, textiles, transportation equipment, iron and steel and mineral products. PAP, CHM and FOO are more variable, as might be expected by the large levels and trends in the markups and the variations in results (and sometimes strange results) found for these industries compared to others by researchers such as Hall and DHP.

The impacts of fixity of capital and labor individually on the markup can be expressed in terms of the $\epsilon$ PRAT, $K$ and $\epsilon$ PRAT, $L$ measures presented in Table 5. The elasticity of PRAT with respect to $\mathrm{K}$ changes is greater than zero for all industries except CHM. This suggests that for most industries increasing capital supports larger markups. This is consistent with the finding in Morrison [1988d] that the more substantial capital investment in the Japanese manufacturing sector has allowed higher markups than in the U.S. Such a result is robust (does not fluctuate in sign or very much in value over time) for all industries except PAP. This, and the negative values for the chemical industry, which imply that additional capital is not effective at generating profits, could possibly be a result of pollution abatement capital regulations that stimulate capital investment that is not "productive" in the sense of producing measured output and therefore profit. The elasticities are not very large, however, ranging between .02 and .13 , and there is no clear durable-nondurable pattern.

The evidence is similar for labor, where the elasticities are all positive except for PAP (which is negative for the entire sample). Increasing 
the labor force, possibly from relaxing constraints on adjustment, therefore also supports larger markups, except in the paper industry where labor may not be very important for production. These values also tend to be larger than those for capital.

As DHP suggest, therefore, fixity of both capital and labor has an important impact on the markup through the utilization of the fixed inputs, and it appears that the potential to invest in either capital or labor increases the potential markup over marginal costs. It follows that flexibility of adjustment may augment markups; fixity of $\mathrm{K}$ and $\mathrm{L}$ constrains profitability. The markup would tend to be larger with instantaneous adjustment, but could potentially have greater fluctuations because in downturns the excess inputs would be costly for the firm, as suggested by the adjustment by $\mathrm{CU}_{\mathrm{c}}$ above.

Other "supply shocks" or shifts in the cost curves that affect the markup include fluctuations in input prices and technical change. For input prices, it would seem plausible that $P_{E}$ or $P_{M}$ increases would cause costs to increase and PRAT to decrease. This is confirmed by the estimates; the $P_{M}$ elasticities are all negative and large, which would be expected with the large share of materials in costs, and the $P_{E}$ elasticities are negative except in the food industry, where they are not robust over time, and iron and steel, where they are robust but small. In the latter case, for this energy intensive industry, large cost expansions from energy price increases seems to stimulate output changes sufficient to move firms to a point of more inelastic demand. This, plus the reduced elasticity for transportation equipment compared to the norm, suggests a weaker impact on the price margin for durable 
compared to nondurable goods industries. The technical change (or time) impact is positive in all industries except FOO (for which it is not robust) and PAP, which may suggest increasing competition over time in these industries.

Demand "shocks", or changes in the arguments of the demand function, also have important impacts on the price ratio. For example, the effect of import competition can be assessed through the $\epsilon$ PRAT,PIM elasticity. This elasticity is very robust, and is positive and large for all industries except NMP, for which it is positive and small, and PAP, which is negative and small. There is no discernable durable-nondurable pattern. The numbers imply that in general when import prices increase, Canadian markups increase. One might think that this impact would be largest for those products which have the most international markets. This appears a reasonable interpretation of the results found; the market for paper products is not particularly competitive internationally, which is also reflected in the large fluctuations in PRAT discussed above. An alternative interpretation of this is consistent with the analysis of the export market in Schembri [1988], where that market did not meet changes in exchange rates with corresponding changes in export prices but instead absorbed the changes. Since the Canadian paper market serves most Canadian needs and also exports heavily to the U.S., and import price changes could refect changes in the U.S. - Canada exchange rate, the small elasticity might be evidence of such a a stable domestic price. Finally, note that these elasticities imply that, for example, for total manufacturing in 1978 $\epsilon_{\mathrm{YP}}, \mathrm{PIM}^{-5} .5526$; the elasticity of demand increases substantially (toward zero) when PIM increases, so demand becomes more inelastic. 
Another demand variable which is focused on by DHP is unemployment. Here is appears than unemployment fluctuations have a limited impact on price margins; the value is negative for most industries, especially the nondurable industries, but is negligible. Small positive values occur for PAP and two of the three durable industries, IS and NMP. The interest rate pattern on markups is similar; no clear pattern emerges and the values are quite small.

The impact of CPI and EXP on price margins is more similar to that for the import price. The elasticities with respect to both of these variables are positive and quite large everywhere (especially for nondurable industries) except IS for CPI and TEX for EXP, both of which are robust. These measures imply, as for PIM, that the demand function becomes significantly more inelastic when these arguments of the demand function increase.

No clear durable-nondurable pattern appears from these elasticities. This is somewhat surprising since industries in these categories may have very different production structures. In the durable industries, (especially IS) the firm does not really shut down, often different shifts are used, and production is very capital and energy intensive. One would think this would elicit a different type of price response to exogenous shocks than for firms in the more labor intensive food or textiles industries. Instead the impacts are reasonably consistent across industries; demand variables such as CPI, EXP, and PIM and one cost determinant, $P_{M}$, have a large robust effect on the price margin, and $r, U N$, and $t$ have a small and indeterminate impact.

A clearer picture of what stimulates counter-or pro-cyclicality can be obtained by looking at the PRAT as compared to the $\mathrm{CU}_{\mathrm{c}}$ and $\varepsilon_{\mathrm{CY}} \mathrm{L}^{\mathrm{m}}$ elasticities. For example, with changes in $\mathrm{PE}_{E}$, PRAT and $\mathrm{CU}_{c}$ tend to move in the same 
direction (down with an increase in $P_{E}$ ). For FOO, CHM and TRQ this works in the opposite direction but the values are not robust and tend to be small. The only industry for which robust opposite impacts on PRAT and $\mathrm{CU}_{c}$ are observed is the iron and steel industry. This is not the case for ${ }^{\epsilon} \mathrm{CY}$; these move in the same direction as for PRAT, except for FOO, which is not robust, and TRQ. There does not appear to be any strong durable-nondurable trend, and, in fact, no clear correspondence occurs with correlations between $\mathrm{CU}_{c}$ and PRAT above.

The tendency for the PRAT and CU elasticities to be the same sign is quite pervasive. This implies that the overall tendency given an exogenous shock is procyclical variations in PRAT and $\mathrm{CU}_{c}$. In most industries, however, this trend is overwhelmed by the few variables which push PRAT and $\mathrm{CU}_{\mathrm{c}}$ in opposite directions, resulting in observations of an inverse relationship between these indicators. For example, for total manufacturing, the inverse responses to changes in the labor force appear to have had a large enough impact to generate overall countercyclicality. By contrast, in the iron and steel industry the reversed responses to changes in energy prices and technical change are not sufficient to counteract the overall procyclical nature of relationship between PRAT and $\mathrm{CU}_{c}$; this may stem from the large positive changes in response to fluctuations in $P_{M}$, capital investment, CPI, EXP, and PIM.

In terms of demand as compared to supply (cost) shocks, changes in arguments of the demand function almost always cause parallel movements in $\mathrm{CU}_{\mathrm{c}}$ and PRAT. Except for the impact of unemployment on the food industry, which is very small, the only exception to this is for the paper industry. In this 
industry virtually all demand shocks have opposite, although small, impacts. Countercyclicality therefore appears to arise primarily from cost rather than demand shifts. For example, for total manufacturing, labor force changes appear to have been the driving force toward countercyclical price margins. A similar impact exists for the. TRQ and NMP industries. Moreover, capital stock changes seem to have had an important countercyclical effect on the food, textiles and mineral products industries, since the impact of capital increases is to increase PRAT but decrease $\mathrm{CU}_{\mathrm{c}}$. The combined capital and labor effect is sufficient to cause countercyclicality to be observed for the mineral products industry. 17 In reverse, although for the chemical industry $\mathrm{K}$ and $L$ changes work in the same direction for PRAT and $\mathrm{CU}_{c}, t$ and $\mathrm{P}_{E}$ changes are sufficient to counteract this.

For returns to scale the reverse is found. In particular, the $\epsilon_{\mathrm{CY}}{ }^{\mathrm{L}}$ response to changes in exogenous variables generally is opposite to the PRAT changes, causing the strong inverse responses discussed in terms of the correlations above. This association between PRAT and $\epsilon \mathrm{CY}^{\mathrm{L}}$ is quite pervasive; very few exogenous changes counteract this tendency.

\section{Concluding Comments}

This paper has provided an integrated framework for measuring markup levels and their deviations in response to demand and cost (supply) changes facing the firm, and has used it to assess the levels of and impacts on markups for various Canadian durable and nondurable manufacturing industries.

17 Note that for fixed output and labor stock levels $\mathrm{CU}_{c}$ must decline with increases in $\mathrm{K}$. However, positive values of ${ }^{\epsilon} \mathrm{CU}, \mathrm{K}$ do arise because of the short run profit maximizing changes in output implied in the elasticity. 
A variety of important demand and cost considerations have been incorporated into this markup model. As suggested by Domowitz, Hubbard and Peterson $[1987,1988]$ in the U.S. context, intermediate inputs are significant, for energy and materials prices have a strong impact on the markup ratio. In addition, fixity of both capital and labor contribute important insight for explaining observed cyclical behavior of the markup. On the demand side, the emphasis by DHP on import competition is supported; this seems an important determinant of the ability to establish high markups since when import prices increase markups rise. Unemployment, however, does not appear to have a large effect on the markup.

Estimated markups are within a reasonable range, generally between $10 \%$ and $25 \%$ but increasing to up to $85 \%$ in the paper industry in 1972. These markups tend to increase over time and appear cyclical; most industries experienced the greatest markups in 1971-73 and 1977-79, with significant downturns in 1974-75. The overall cyclical tendency, in terms of correlation with capacity utilization measures, is that the markup ratio is countercyclical, especially in the individual nondurable goods industries. Aggregated data, however, suggests more strong countercyclical behavior in durable good manufacturing. In addition, most exogenous shocks drive the price margin and capacity utilization in the same direction, so procyclical behavior is clearly possible for any of these industries, depending on the exogenous shock stimulating the cyclical change.

The results also suggest that perceived profitability from markups appears to arise primarily from scale economies, in the sense that when the markup ratio is adjusted by scale economies the ratio closely approximates 
one. This is consistent with lower markup measures found in studies that assume constant returns to scale. Scale economies, therefore appear to be the most important cost characteristic to take into account to "explain" markups, as suggested by $\mathrm{Hall}$ [1988b]. In particular, fluctuations in capacity utilization do not absorb the profits implied by positive price margins; they may in fact augment the difference. This is consistent with the potential for procyclical markups. Appropriate cost conditions therefore are important for inelastic demand to generate profits; cost characteristics captured in our measure of scale economies counteract potential profitability. These cost conditions may also have substantial implications for the impacts of trade policy such as the recently enacted free trade agreement between the $U$.S. and Canada, as Rao [1988] has noted. In addition, cost characteristics appear more important than demand determinants for generating observed countercyclical markups. Changes in arguments of the demand function instead appear to induce procyclicality. 
Table 1

Price Ratio Measures

$\mathrm{PY}_{\mathrm{Y}} / \mathrm{MC}$

MAN

Foo

TEX

PAP

CHM

IS

TRQ

NMP

$\begin{array}{lllllllll}1960 & 1.066 & 1.161 & 1.076 & 1.123 & 1.076 & 1.108 & 1.024 & 1.189 \\ 1961 & 1.076 & 1.151 & 1.082 & 1.114 & 1.079 & 1.111 & 1.053 & 1.147 \\ 1962 & 1.087 & 1.156 & 1.088 & 1 . .90 & 1.106 & 1.118 & 1.074 & 1.156 \\ 1963 & 1.105 & 1.158 & 1.098 & 1.145 & 1.125 & 1.128 & 1.086 & 1.167 \\ 1964 & 1.122 & 1.173 & 1.108 & 1.169 & 1.150 & 1.136 & 1.094 & 1.187 \\ 1965 & 1.134 & 1.188 & 1.113 & 1.219 & 1.163 & 1.122 & 1.100 & 1.181 \\ 1966 & 1.143 & 1.182 & 1.127 & 1.243 & 1.216 & 1.137 & 1.108 & 1.204 \\ 1967 & 1.157 & 1.209 & 1.134 & 1.324 & 1.219 & 1.138 & 1.106 & 1.209 \\ 1968 & 1.174 & 1.250 & 1.144 & 1.388 & 1.291 & 1.170 & 1.102 & 1.215 \\ 1969 & 1.191 & 1.249 & 1.167 & 1.449 & 1.410 & 1.166 & 1.112 & 1.232 \\ 1970 & 1.199 & 1.247 & 1.176 & 1.513 & 1.398 & 1.134 & 1.190 & 1.236 \\ 1971 & 1.229 & 1.286 & 1.193 & 1.698 & 1.355 & 1.140 & 1.085 & 1.264 \\ 1972 & 1.249 & 1.258 & 1.230 & 1.849 & 1.431 & 1.175 & 1.103 & 1.312 \\ 1973 & 1.231 & 1.163 & 1.241 & 1.793 & 1.618 & 1.213 & 1.127 & 1.368 \\ 1974 & 1.180 & 1.145 & 1.216 & 1.370 & 1.345 & 1.153 & 1.170 & 1.326 \\ 1975 & 1.186 & 1.164 & 1.220 & 1.379 & 1.250 & 1.152 & 1.149 & 1.299 \\ 1976 & 1.197 & 1.235 & 1.197 & 1.546 & 1.287 & 1.158 & 1.129 & 1.296 \\ 1977 & 1.285 & 1.227 & 1.239 & 1.540 & 1.331 & 1.150 & 1.124 & 1.280 \\ 1978 & 1.237 & 1.255 & 1.253 & 1.770 & 1.542 & 1.217 & 1.137 & 1.330 \\ 1979 & 1.220 & 1.252 & 1.238 & 1.591 & 1.449 & 1.188 & 1.166 & 1.323 \\ 1980 & 1.200 & 1.297 & 1.237 & 1.475 & 1.378 & 1.224 & 1.165 & 1.308 \\ 1981 & 1.182 & 1.333 & 1.235 & 1.479 & 1.404 & 1.186 & 1.160 & 1.277 \\ 1982 & 1.193 & 1.387 & 1.224 & 1.757 & 1.355 & 1.227 & 1.164 & 1.245\end{array}$


Table 2

PRAT Adjusted for Capacity Utilization

$\mathrm{CU}_{c} \mathrm{pY}_{\mathrm{Y}} / \mathrm{MC}$

MAN FOO

$\begin{array}{lrrrrrrrr}1960 & 1.061 & 1.223 & 1.077 & 1.280 & 1.171 & 1.176 & .977 & 1.270 \\ 1961 & 1.093 & 1.132 & 1.096 & 1.285 & 1.145 & 1.162 & 1.080 & 1.148 \\ 1962 & 1.111 & 1.155 & 1.110 & 1.316 & 1.193 & 1.170 & 1.117 & 1.133 \\ 1963 & 1.141 & 1.151 & 1.131 & 1.234 & 1.219 & 1.196 & 1.132 & 1.161 \\ 1964 & 1.177 & 1.182 & 1.138 & 1.260 & 1.249 & 1.177 & 1.139 & 1.183 \\ 1965 & 1.164 & 1.245 & 1.137 & 1.298 & 1.229 & 1.079 & 1.137 & 1.182 \\ 1966 & 1.166 & 1.181 & 1.144 & 1.337 & 1.282 & 1.091 & 1.140 & 1.169 \\ 1967 & 1.176 & 1.248 & 1.147 & 1.409 & 1.247 & 1.090 & 1.128 & 1.194 \\ 1968 & 1.188 & 1.334 & 1.161 & 1.404 & 1.333 & 1.210 & 1.107 & 1.206 \\ 1969 & 1.205 & 1.322 & 1.192 & 1.444 & 1.474 & 1.195 & 1.112 & 1.214 \\ 1970 & 1.204 & 1.292 & 1.198 & 1.500 & 1.423 & 1.012 & 1.061 & 1.217 \\ 1971 & 1.241 & 1.358 & 1.207 & 1.683 & 1.351 & 1.021 & 1.038 & 1.291 \\ 1972 & 1.255 & 1.298 & 1.234 & 1.807 & 1.425 & 1.109 & 1.060 & 1.349 \\ 1973 & 1.244 & .995 & 1.259 & 1.798 & 1.791 & 1.174 & 1.109 & 1.435 \\ 1974 & 1.182 & .838 & 1.228 & 1.500 & 1.352 & 1.036 & 1.185 & 1.350 \\ 1975 & 1.194 & .984 & 1.235 & 1.526 & 1.184 & 1.003 & 1.167 & 1.301 \\ 1976 & 1.190 & 1.218 & 1.156 & 1.600 & 1.206 & 1.012 & 1.119 & 1.283 \\ 1977 & 1.285 & 1.171 & 1.252 & 1.564 & 1.233 & .914 & 1.102 & 1.223 \\ 1978 & 1.246 & 1.239 & 1.272 & 1.740 & 1.497 & 1.203 & 1.127 & 1.326 \\ 1979 & 1.226 & 1.205 & 1.244 & 1.584 & 1.366 & 1.122 & 1.171 & 1.272 \\ 1980 & 1.206 & 1.276 & 1.246 & 1.532 & 1.273 & 1.215 & 1.176 & 1.239 \\ 1981 & 1.170 & 1.330 & 1.243 & 1.561 & 1.283 & 1.091 & 1.167 & 1.145 \\ 1982 & 1.186 & 1.417 & 1.252 & 1.755 & 1.187 & 1.217 & 1.172 & 1.154\end{array}$


Table 3

PRAT Adjusted for Scale Economies

$\epsilon_{\mathrm{CY}} \mathrm{L}_{\mathrm{PY}} / \mathrm{MC}$

MAN

TEX

PAP

CHM

IS

TRQ

NMP

1960

1961

1962

1963

1964

1965

1966

1967

1968

1969

1970

1971

1972

1973

1974

1975

1976

1977

1978

1979

1980

1981

1982
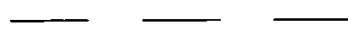

.995

1.036

.998

1.061

1.001

1.056

1.009

1.059

1.016

1.055

1.018

1.038

1.020

1.057

1.023

1.039

1.028

1.018

1.034

1.022

1.033

1. 029

1.044

1.013

1.052

1.027

1.043

1.114

1.019

1.175

1.017

1.132

1.064

1.021

1.079

1.054

1.064

1.028

1.076

1.018

1.055

1.007

1.032

1.000

.998

$$
.977
$$

.975

.905

.902

.974

.893

$.974 \quad .911$

.911

.975

.914

.921

.97

.984

.916

.985

.937

.988

.963

.993

.988

.998

1.002

1.001

1.067

1.006

1. 128

1.005

1.110

.999

.939

1.007

1.000

.933

1.003

1.009

.992

1. 007

1.105

.998

1.025

.997

.963

.994

.935

1.003

1.036
.917

.020

1.023

1.015

.928

1.010

.928

1.001

.930

1.003

1.018

.942

1.008

1.002

.965

.965

1.016

1.012

.973

.938

1.022

1.042

1.031

1.062

1.000

1.062

1.005

.956

1.023

.991

1.017

.963

1.024

1.007

1.028

.942

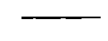

$-$

1.056

$.987 \quad 1.045$

$.998 \quad 1.046$

$1.001 \quad 1.047$

$1.004 \quad 1.052$

1.006

1.047

$1.009 \quad 1.053$

$1.006 \quad 1.052$

$1.003 \quad 1.051$

$1.007 \quad 1.053$

$.997 \quad 1.052$

$.994 \quad 1.055$

$1.002 \quad 1.062$

$1.013 \quad 1.071$

$1.033 \quad 1.072$

$1.021 \quad 1.070$

$1.011 \quad 1.074$

$1.008 \quad 1.077$

$1.013 \quad 1.083$

$1.026 \quad 1.085$

$1.023 \quad 1.084$

$1.018 \quad 1.089$

$1.017 \quad 1.083$ 
Table 5

Price Ratio, Capacity Utilization and Returns to Scale Elasticities (reported for 1978)

\begin{tabular}{|c|c|c|c|c|c|c|c|c|}
\hline & MAN & $\underline{F 00}$ & $\underline{I E X}$ & PAP & $\underline{\mathrm{CHM}}$ & IS & TRQ & $\underline{N M P}$ \\
\hline${ }^{\epsilon} \mathrm{PRAT}, \mathrm{PE}$ & -.0325 & .0095 & -.0215 & -.0332 & -.1228 & .0125 & -.0028 & -.0493 \\
\hline${ }^{\epsilon}$ PRAT, PM & -.8895 & -1.2058 & -.6146 & -1.1073 & -1.6573 & -.3201 & -.6892 & -.4824 \\
\hline${ }^{\epsilon}$ PRAT, $\mathrm{K}$ & .0533 & .1308 & .0171 & .0864 & -.1525 & .1304 & .0249 & .1023 \\
\hline${ }^{\epsilon}$ PRAT , L & .0567 & .3925 & .2130 & -.2347 & .5019 & .1064 & .0565 & .2042 \\
\hline${ }^{\epsilon}$ PRAT , $t$ & .0014 & -.0040 & .0072 & -.0064 & .0038 & .0081 & .0014 & .0034 \\
\hline${ }^{\epsilon}$ PRAT , CPI & .4245 & .2553 & .6155 & .5156 & .6868 & -.2358 & .2484 & .2917 \\
\hline${ }^{\epsilon} \mathrm{PRAT}, \mathrm{EXP}$ & .1786 & .5124 & -.2905 & .7552 & .0542 & .2787 & .0626 & .2434 \\
\hline${ }^{\epsilon}$ PRAT , r & -.0143 & .0042 & .0052 & -.0712 & .1452 & .0146 & .0080 & -.0323 \\
\hline${ }^{\epsilon}$ PRAT , PIM & .3332 & .4247 & .3059 & -.0662 & 1.0391 & .2502 & .3772 & .0289 \\
\hline${ }^{\epsilon} \mathrm{PRAT}, \mathrm{UN}$ & -.0167 & -.0022 & -.0083 & .0619 & -.0070 & .0050 & -.0344 & .0118 \\
\hline$\epsilon_{\mathrm{CU}, \mathrm{PE}}$ & -.0058 & -.0068 & -.0119 & -.0456 & .0280 & -.0991 & .0002 & -.1184 \\
\hline${ }^{\epsilon} \mathrm{CU}, \mathrm{PM}$ & -.1278 & -1.7923 & -.4353 & .3904 & -.8739 & -1.4483 & -.3824 & -.3769 \\
\hline${ }^{\epsilon} \mathrm{CU}, \mathrm{K}$ & .0147 & -.0696 & -.0585 & .3386 & -.2606 & .1282 & .0049 & -.0776 \\
\hline${ }^{\epsilon} \mathrm{CU}, \mathrm{L}$ & -.0602 & .2136 & .0116 & -.0656 & .2240 & .0758 & -.0449 & -.0806 \\
\hline${ }^{\epsilon} \mathrm{CU}, \mathrm{t}$ & .0003 & -.0099 & .0038 & -.0028 & -.0073 & -.0469 & -.0021 & .0006 \\
\hline${ }^{\epsilon} \mathrm{CU}, \mathrm{CPI}$ & .1849 & .4255 & .7533 & -.0091 & .4671 & -1.5444 & .2179 & .4769 \\
\hline${ }^{\epsilon} \mathrm{CU}, \mathrm{EXP}$ & .0778 & .8541 & -.3555 & -.0134 & .0368 & 1.8248 & .0582 & .3979 \\
\hline${ }^{\epsilon} \mathrm{CU}, \mathrm{r}$ & -.0062 & .0070 & .0063 & .0013 & .0858 & .0956 & .0063 & -.0528 \\
\hline${ }^{\epsilon} \mathrm{CU}, \mathrm{PIM}$ & .1451 & .7078 & .3744 & .0012 & .7067 & 1.6384 & .3310 & .0472 \\
\hline${ }^{\epsilon} \mathrm{CU}, \mathrm{UN}$ & -.0068 & $\cdot .0033$ & -.0083 & -.0007 & -.0043 & .2861 & -.0282 & .0141 \\
\hline${ }^{\epsilon} \mathrm{CYL}, \mathrm{PE}$ & .0200 & -.0181 & .0127 & .0125 & .0329 & .0427 & -.0038 & .0978 \\
\hline$\epsilon_{\mathrm{CYL}, \mathrm{PM}}$ & .4547 & 2.4229 & .4509 & .2002 & 1.6601 & .9768 & .3214 & .4145 \\
\hline${ }^{\epsilon} \mathrm{CYL}, \mathrm{K}$ & -.1032 & -.0826 & .0464 & -.3955 & .3421 & -.2467 & -.0253 & -.0554 \\
\hline${ }^{\epsilon} \mathrm{CYL}, \mathrm{L}$ & .0278 & -.6896 & -.2319 & .1477 & -.6642 & -.1638 & -.0271 & -.1599 \\
\hline${ }^{\epsilon} \mathrm{CYL}, \mathrm{t}$ & -.0010 & .0140 & -.0047 & .0033 & -.0032 & .0275 & .0013 & -.0022 \\
\hline${ }^{\epsilon} \mathrm{CYL}, \mathrm{CPI}$ & -.2186 & -.5119 & -.4487 & -.0958 & -.6532 & .7815 & -.1140 & -.2811 \\
\hline${ }^{\epsilon} \mathrm{CYL}, \mathrm{EXP}$ & -.0920 & -1.0275 & .2118 & -.1404 & -.0515 & -.9235 & -.0305 & -.2345 \\
\hline${ }^{\epsilon} \mathrm{CYL}, \mathrm{r}$ & .0074 & -.0084 & -.0038 & .0132 & -.1242 & -.0484 & -.0033 & .0311 \\
\hline${ }^{\epsilon} \mathrm{CYL}, \mathrm{PIM}$ & -.1716 & -.8516 & -.2230 & .0123 & .9883 & -.8291 & -.1732 & -.0279 \\
\hline${ }^{\epsilon} \mathrm{CYL}, \mathrm{UN}$ & .0075 & .0040 & .0049 & -.0074 & .0060 & -.1448 & .0148 & -.0083 \\
\hline
\end{tabular}




\section{References}

Appelbaum, Elie [1979], "Testing Price Taking Behavior", Journal of Econometrics, Vol. 9, No. 3, February, pp. 283-294.

Appelbaum, Elie [1982], "The Estimation of the Degree of Oligopoly Power", Journal of Econometrics, 19, Pp. 287-299.

Berndt, Ernst R., and Mohammed S. Khaled (1979), "Parametric Productivity Measurement and Choice Among Flexible Functional Forms", Journal of Political Economy", Vol. 87, No. 6, pp. 1220-1245.

Berndt, Ernst R., Melvyn Fuss and Leonard Waverman [1980], Empirical Analysis of Dynamic Adjustment Models of the Demand for Energy in U.S. Manufacturing Industries 1947-74, Final Research Report, Palo Alto, California, Electric Power Research Institute, November.

Bils, Mark [1985], "The Cyclical Behavior of Marginal Cost and Price", manuscript, November.

Bils, Mark [1987], "Cyclical Pricing of Durable Luxuries", Working Paper No. 83, University of Rochester, May.

Diewert, W. Erwin [1980], "Symmetry Conditions for Market Demand Functions", Review of Economic Studies, 67, pp. 595-601

Domowitz, Ian. R. Glenn Hubbard, and Bruce C. Petersen [1987], "Market Structure, Durable Goods, and Cyclical Fluctuations in Markups", manuscript, June 1987.

Domowitz, Ian. R. Glenn Hubbard, and Bruce C. Petersen [1988], "Market Structure and Cyclical Fluctuations in U.S. Manufacturing", The Review of Economics and Statistics, Vol. 70, No. 1, February.

Fuss, Melvyn and Leonard Waverman [1986], "The Extent and Sources of Cost and Efficiency Differences Between U.S. and Japanese Automobile Producers", National Bureau of Economic Research Working Paper No. 1849, March.

Hall, Robert E. [1988a], "The Relation Between Price and Marginal Cost in U.S. Industry", Journal of Political Economy, Vo1. 96, No. 5, October, pp. $921-947$.

Hall, Robert E. [1988b], "Increasing Returns; Theory and Measurement with Industry Data", manuscript, presented at the N.B.E.R. Conference on Economic Fluctuations, Cambridge, Massachusetts, October.

Morrison, Catherine J. [1982], "Three Essays on the Dynamic Analysis of Demand for Factors of Production", Ph.D. Dissertation, Vancouver: University of British Columbia Department of Economics, December. 
Morrison, Catherine J. [1986], "Productivity Measurement with Nonstatic Expectations and Varying Capacity Utilization: An Integrated Approach", Journal of Econometrics, Vo1. 33, No. 1/2, October/November 1986, pp. $51-74$.

Morrison, Catherine J. [1988a], "Capacity Utilization and Productivity Measurement: An Application to the U.S. Automobile Industry", Ch. 7 in Applications of Modern Production Theory: Efficiency and Productivity, Ali Dogramaci, ed., Kluwer Nijhoff Publishing: Boston, 1988.

Morrison, Catherine J. [1988b], "Quasi-Fixed Inputs in U.S. and Japanese Manufacturing: A Generalized Leontief Restricted Cost Function Approach", Review of Economics and Statistics, Vol. 70, No. 2, May, pp. 275-287.

Morrison, Catherine J. [1988c], "Subequilibrium in the North American Steel Industries: A Study of Short Run Biases from Regulation and Utilization Fluctuations", Economic Journal, Vol. 98, No. 391, June, pp. 390-411.

Morrison, Catherine J. [1988d], "Markups in U.S. and Japanese Manufacturing: A Short Run Econometric Analysis", manuscript, November.

Morrison, Catherine J. [1988e], "A Framework for Adjusting Productivity Growth Measures: Accounting for Subequilibrium, Returns to Scale and Markups", manuscript, December.

Morrison, Catherine J. and Ernst R. Berndt [1981], Short Run Labor Productivity in a Dynamic Mode1", Journal of Econometrics, Vol. 16, pp. 339-365.

Pindyck, Robert S. and Julio J. Rotemberg [1983], "Dynamic Factor Demands, Energy Use and the Effects of Energy Price Shocks, American Economie Review, Vol. 73, No. 5, December, pp. 1066-1079.

Rao, P. Someshwar [1988], "U.S. -Canada Productivity Gaps, Scale Economies and the Gains from Freer Trade", Economic Council of Canada, Discussion Paper No. 357, Ottawa,. September.

Romer, Paul M. [1986], "Increasing Returns and Long-Run Growth", Journal of Political Economy, 94, October, pp. 1002-1037.

Rotemberg, Julio J,, and Garth Saloner [1986], "A Supergame-Theoretic Model of Business cycles and Price Wars During Booms", Quarterly Journal of Economics, 101 .

Rotemberg, Julio J., and Lawrence H. Summers [1987], "Procyclical Productivity as a Consequence of Inflexible Prices", manuscript, July.

Schembri, Lawrence [1988], "Export Prices and Exchange Rates: An Industry Approach, forthcoming in Trade Policy and Competitiveness, Robert Feenstra, ed., University of Chicago Press.

Shapiro, Matthew, [1988], "Measuring Market Power in U.S. Industry", National Bureau of Economic Research Working Paper \#2212, April. 